\title{
Feeding Rotifers Brachionus plicatilis with microalgae cultivated in Tunisia
}

\author{
C Jabeur ${ }^{1 *}$, A Merghni ${ }^{1}$ and F Kamoun ${ }^{2}$ \\ ${ }^{1}$. High Institute of Biotechnology of Monastir. Laboratory of Analysis, Treatment and valorization of Products \\ and pollutant of Environment. Faculty of Pharmacy. PO Box 74. 5000. Monastir. Tunisia \\ ${ }^{2 .}$ National Institute of Sciences and technologies of the Sea. Center of Monastir
}

\begin{abstract}
In this study we investigated the feeding of rotifers Brachionus plicatilis with different diets. We used different foods: powder spirulina, concentrated Chlorella, commercial food named "culture selco" diluted in various volumes and each of these food modes associated to microalgae. We determined the rotifers density, the daily growth rate and the percentages of eggs for the different diets. The food on live spirulina did not give concluding results. The use of inert food only shows a maximum of eggs rotifers percentage and specific growth rate with concentrated Chlorella and a comparable result with powdered spirulina and selco culture $(P \geq 0,05)$. The maximum of the density of rotifers and eggs percentage were obtained with culture selco associated with microalgae, followed by the food mode using super concentrated Chlorella and lastly the food using the powder spirulina.
\end{abstract}

Key words: Arthrospira platensis, Chlorella, culture of zooplanktons, nutrition, rotifers

\section{Introduction}

Production of zooplankton, a key component of the productive process in a modern hatchery, remains one of the most important obstacles for the development of marine aquaculture. Zooplankton, such us the rotifer "Brachionus plicatilis", was used for several years as a source of animal proteins in larval breeding (Hirata, 1974). Several works were realized to investigate the possibilities of production of these rotifers using various food substrates, in particular algae [1] and yeasts [2]. These types of food permit to obtain relatively appreciable production rates but the rotifers present variable nutritional qualities (Awaïss, 1992). The production of the rotifer "Brachionus plicatilis" on a natural nutritive substrate like spirulina "Arthrospira platensis" presents several advantages due to the fact that it is a natural source concentrated in nutrients for all animals [3]. In addition, this microalgae is used in several fields, such as the larval breeding with a total value of 1 to $10 \%$ of the food, in order to increase the immunological resistance of the larvae [4]. The spirulina is also used in the production of preys like Artemias and Daphnis, in its live form and out of dry powder. This species is known by its high content in protein containing the totality of the amino-acids [5] essentially fatty-acids [6]. It is now cultivated in an industrial scale in several countries such as U.S.A., India, China and Thailand and this because of its highly interesting qualities as a food and its interest for health and wellbeing of human and animal [7].

The aim of this work is to conduct a comparative study of the production of the rotifers using inert food and the spirulina. Various food modes were tested; the spirulina powders, the inert food "culture selco", the Chlorella super-concentrated. Each of these three modes were also investigated with addition of microalgae such as Chlorella minutissima and Picochlorum sp., in order to identify the food model which provide the best rotifers growth rate and eggs percentages.

\section{Biological material}

\section{Material and methods} Rotifers

The specie Brachionus plicatilis used in this study is obtained from a strain of rotifers cultivated in the National Institute of Marine Science and Technology (INSTM, appendix of Monastir, Unit of the live preys). This specie presents 2 different sizes. The small ones (S) measure from 120 to $160 \mu \mathrm{m}$ and the large ones (L) between 250 to $300 \mu \mathrm{m}$ (Barnabé, 1991). They are used in the larval food at a rate of 5 to $30 \mathrm{invidious} / \mathrm{ml}$.

\section{The microalgae}

Three microalgae were used in this study they were as follow:

$\square$ Arthrospira platensis:, it is obtained from the Tunisian farm "Ferme Marine Bio Algues". It was used as a food for rotifers in Erlenmeyer and as an inert food (dry powder form) for rotifers in tanks at the rate of $1 \mathrm{~g}$ of spirulina powder for 1 million of rotifers. 
$\square \square$ Picochlorum sp: belongs to the class of Chlorophycea. It was isolated from a sample taken from the bay of Monastir. In this study, it was used as a food for rotifers in Erlenmeyer (2L), in a plastic bag (60L) and as a supplement in a rotifer tank at the rate of $5 \mathrm{~L} /$ day.

$\square \square$ Chlorella minutissima: belongs to the class of Chlorophycea. It is characterized by an exceptional concentration in chlorophyll, and was used as a food for rotifers reared in a plastic bag (60L) and as a supplement in a rotifer tank $(5 \mathrm{~L} /$ day every morning)

\section{Inert food}

$\square \square$ Culture selco: fine particles, which must be solubilized in the water before distribution. The daily ration was calculated according to the concentration of rotifers in the tank using the following formula:

The daily ration of culture selco $=0.4 \mathrm{~g} \mathrm{C.S} * 1$ million $\mathrm{R}$.

Where; C.S: Culture selco and R: Rotifer.

$\square$ Powder spirulina: fine dry particles, which were micronized, filtered, and solubilized in the water before distribution. The daily ration is calculated according to the following formula:

The daily ration of powder spirulina $=1 \mathrm{~g}$ P.S $* 1$ million R.

Where; P.S: Powder Spirulina and R: Rotifer.

$\square \square$ Concentrated Chlorella: It a fresh water specie, imported from Japan. Its concentration was 13 billion cells by milliliter. The daily ration is given according to the following formula:

The daily ration of concentrated Chlorella $=1 \mathrm{ml} \mathrm{C.C} / 1$ million R.

Where; C.C: Concentrated Chlorella and R: Rotifer.

\section{Experimental protocol}

Culture of the rotifer

First, we maintained the strains of rotifers in Erlenmeyer flasks with a volume of $50 \mathrm{ml}$ which contained mature microalgae. Then we passed through intermediate breeding in Erlenmeyer 2L. After the breeding flasks we moved to the production of rotifers in a plastic bag of $60 \mathrm{~L}$, containing microalgae in exponential growth phase. When the density of rotifers reached its maximum, they were then filtered to pass in small tanks (180L).

Breeding took place in a controlled environment with a temperature of $24 \pm 1^{\circ} \mathrm{C}$, salinity was kept at $20 \%$ and the light at 1000 lux. The sea water used to fill the tanks was simultaneously filtered through filters in $50 \mu \mathrm{m}$, $5 \mu \mathrm{m}$ and $1 \mu \mathrm{m}$. It then passed through a UV sterilizer. This water was also chlorinated at the rate of $5 \mathrm{ppm}$ then de-chlorinated by a molar solution of thiosulfate sodium. The tanks were supplied by bubbling air to ensure agitation and to maintain rotifers suspended.

\section{Culture of the microalgae}

In this study, the cultures were maintained under the growth algae optimal conditions to ensure the multiplication of the algae cells and their growths (table 1).

\section{Preparation of diets}

First, various diets were used such as inert food like culture selco, micro-fine spirulina, or concentrated Chlorella. Second, we added micro-algae to each inert food. For each type of food, three tanks were prepared to determine the assimilation of this food by the rotifers (table 2).

To recapitulate the diets tested are:

1- Alive Spirulina

2- Spirulina powder

3- Spirulina powder with microalgae

4- Culture selco

5- Culture selco with microalgae

6- Microalgae

7- Concentrated Chlorella

8- Concentrated Chlorella with microalgae

\section{Follow up of growth \\ Microalgae growth}

A sample was taken every day to monitor of the Picochlorum $s p$. culture growth. A cellular enumeration was done by optical microscope using the Malassez cell,. Cellular concentrations were calculated according to the following formula: 
With: C: concentration and $\mathrm{N}$ : average number of cells

$$
\mathrm{C}=\mathrm{N}^{*} 10^{5} \text { cells } / \mathrm{ml} .
$$

To monitor the growth of Spirulina cultures, we measured the optical density at a $680 \mathrm{~nm}$ wavelength.

\section{Rotifers growth}

A sample of $250 \mu \mathrm{l}$ was removed from the flasks and another from the tanks for counting rotifers under a dissecting microscope. Then we multiplied by the tank volume to determine the rotifer population density.

The percentage of eggs was determined by dividing the number of females carrying eggs by the total number of rotifers found in the volume of $250 \mu$ then multiply by 100 .

The daily Specific Growth Rate was calculated using the following equation described by [8]:

$$
\mathrm{SGR}=(\ln \mathrm{Nt}-\ln \mathrm{N} 0) / \mathrm{t}
$$

where: $\mathrm{SGR}=$ specific growth rate; $\mathrm{Nt}=$ rotifer density after culture period $\mathrm{t}$ (individuals $\mathrm{ml}-1$ ); $\mathrm{N} 0=$ initial rotifer density (individuals $\mathrm{ml}^{1}$ ); $\mathrm{t}=$ culture period (day).

\section{Data analysis}

The StatView statistical program (version 5.0) was used for data analysis. Analysis of Variance (ANOVA) was used to determinate any significant differences between tested variables of populations densities, daily specific growth rate and of rotifer eggs percentages. All significance tests were performed at $\mathrm{P}=0.05$.

\section{Results}

Growth of rotifers nourished with live food in low volumes (Erlenmeyer)

Culture of rotifers with microalgae

The results of the growth of the rotifers in 3 Erlenmeyer fed by the microalgae, Picochlorum sp., were represented in figure 1. Evolution of the microalgae growth in the Erlenmeyer showed an increasing curve with a maximum at the tenth day followed by a phase of reduction. The rotifers were introduced when the microalgae were in full growth phase. The growth of the latter followed an exponential curve and corresponded to the phase of increase in rotifers. Indeed the density of the rotifers exceeded the 400 individuals/ml towards D17.

\section{Culture of rotifers with a live spirulina}

It was noted that the density of rotifers cultivated in the 3 Erlenmeyer containing the spirulina decreased from 16 to 5 rotifers $/ \mathrm{ml}$ after eight days (figure 2). This decrease was likely due to the fact that the food with spirulina proposed was not accepted by the rotifers. The bacteriological analysis of the distributed sample showed a contamination.

\section{Growth of rotifers fed by composed aliment in big volumes (tanks $180 \mathrm{~L}$ )}

Rotifers fed with microalgae + inert food:

Density of the rotifers

For the three food modes tested (microalgae + culture selco; microalgae+ spirulina powder and microalgae+ concentrated Chlorella) (figure 3), we noted an increasing evolution of the density from D0 to D4. The best growth was obtained for the first food mode (microalgae + culture selco) with a maximum density of 208 rotifers $/ \mathrm{ml}$, followed by the diet of microalgae + concentrated Chlorella, where the density reached 150 rotifers $/ \mathrm{ml}$. The growth of the rotifers, obtained with a food containing microalgae + powder spirulina, also presented an increasing evolution but less than the others diets. Indeed, the maximum density obtained was about 103 rotifers $/ \mathrm{ml}$.

\section{Specific Growth Rate of rotifers}

Variation of the average daily Specific Growth Rate of the rotifers according to composed food modes (figure 4) shows that the rotifers fed with the second food mode (microalgae + spirulina powder) had a growth rate of $15.21 \%$. It was slightly lower than that obtained with the other diets with $20.08 \%$ for the mode microalgae + concentrated Chlorella and $17.43 \%$ for that of the microalgae + selco culture. However these differences remain non significant $(\mathrm{P} \geq 0.05)$.

\section{Eggs percentages}

Concerning the percentage of rotifers eggs (figure 5), the best results were obtained with the mode containing the microalgae + selco culture with a percentage of $30 \%$, which was significantly different compared to the others percentages $(\mathrm{P}<0.05)$. The percentage of eggs of rotifers fed with microalgae + spirulina powder was of $21 \%$. It was close that obtained with microalgae + concentrated Chlorella $(22 \%)(\mathrm{P} \geq 0.05)$. 


\section{Rotifers fed with inert food only \\ Density of rotifers}

The culture of rotifers fed on inert food only on (selco culture, powder spirulina and concentrated Chlorella) showed a slightly increasing density at the beginning of the culture which declined rapidly with time for the three tested modes (Figure 6). Indeed, for rotifers fed with selco culture only, their density varied from 63 at D0, to reach a maximum of 77 rotifers $/ \mathrm{ml}$ at D2. At D3, it decreased to 49 rotifers $/ \mathrm{ml}$. The same result was obtained for the second food mode (powder spirulina) where the density of rotifers fluctuated from 63 at D0 to 90 at D2, it decreased to 55 at D3. Rotifers fed with the concentrated Chlorella followed the same shape curve, but the density was higher and increased during the first three days of breeding from 55 to 138 and started to decrease on $\mathrm{D} 4$, where the density reached 122 rotifers $/ \mathrm{ml}$.

\section{Specific Growth Rate of rotifers}

Rotifers fed with the concentrated Chlorella presented a better specific growth rate (17.59\%), which was significantly different $(\mathrm{P}<0.05)$ for these fed on spirulina mode (with a rate about $-4.51 \%$ ) and on selco culture mode (with a rate of -10.97 ) (Table 3).

The specific growth rate of rotifers using powdered spirulina or selco culture mode didn't show a significant difference $(\mathrm{P} \geq 0,05)$.

\section{Eggs percentages}

The best result was obtained using a food mode containing concentrated Chlorella where the percentage of eggs was $26 \%$, which was significantly different from feeding on selco culture $(19 \%)(\mathrm{P}<0.05)$ and on powdered spirulina $(20 \%)(\mathrm{P} \geq 0.05)$. But the powdered spirulina compared to selco culture did not show a significant difference $(\mathrm{P} \geq 0.05)$.

\section{Discussion}

Traditionally, algae species like Dunaliella, Isochrysis, Monochrysis, and Chlorella were often used as a food for the rotifers because of their small size which is lower than $20 \mu \mathrm{m}$ [9]. [10] showed that these algae have also a high nutritional effect.

Several diets were experimented in different studies to perform the growth of rotifers. [11] showed significant effects on growth rate and viability of rotifers using other microalgae. [12] showed that yeast (Saccharomyces cerevisiae) when mixed with green algae (Chlorella vulgaris and Scenedesmus acutus), was appropriate for growing freshwater rotifers.

The xenic cultures of marine rotifer Brachionus "Cayman" fed on microalgae (Tetraselmis suecica) performed significantly better than those fed on baker's yeast (Saccharomyces cerevisiae), when comparing population density, growth rate and egg ratio [13]. A significant effect of L-carnitine addition was only found in yeast-fed cultures. [14] developed a test system with genotobiotically grown Brachionus plicatilis for the evaluation of the microbial functions and the nutritional value of different feed types. The authors found that all of the tested microbial communities were able to increase the rotifer growth rate when yeasts were used as a major food source.

The study of [15] showed that a single addition of a mixture of three probionts (Phenylobacterium sp., Gluconobacter sp., and Paracoccus denitrificans) had no significant effect on rotifer growth in batch culture, but a rotifer growth rates was significantly higher when Nannochloropsis oculata paste was provided instead of a yeast-based diet.

The inert food like the powdered spirulina, which has the advantage to be available in the market, is also used for the mass culture of zooplanktons. Indeed, the spirulina is employed in the production of live preys like Artemias and Daphnis. [16] showed that for the culture of Artemia salina, the use of powder atomized of the spirulina Spirulina maxima optimizes the growth and the survival. A satisfactory rotifer reproduction was demonstrated by using spirulina as a supplement in alimentation with microalgae [17].

In this study, we tested the assimilation of the spirulina by the rotifers cultivated in small volumes (Erlenmeyer of 2L) compared to the other species of microalgae (Picochlorum sp., Chlorella minutissima). The results showed that the rotifers could not incorporate the spirulina as a live food. Indeed, Spirulina is more difficult to be filtered than the mono-cellular algae [16]. The size of the algae is a considerable factor which affects the development of this type of zooplankton. According to [18], the rotifers (from the group of the Brachionides) cannot filter particles with a size higher than $18 \mu \mathrm{m}$. However the tested spirulina, in spite of its fine crushing, has probably a higher size. In addition, microbiological analyses carried out on spirulina, culture showed the presence of pathogenic germs like total coliforms, fecal coliforms and anaerobic sulfato-reducing. These kinds of bacteria could also contribute to the decrease of rotifers density. 
For the culture of the rotifers in great volumes (vats of $200 \mathrm{~L}$ ), the use of a food mode composed of the microalgae and powdered spirulina, contributed to the rotifers growth rate in a similar way than obtained with microalgae enriched by culture selco or by the Chlorella concentrated.

Moreover, the use of the powdered spirulina alone as a food for the rotifers showed an increase of the rotifers density showing that the latter could assimilate them. In addition, this density was slightly better than that obtained with culture selco but lower than the one using the concentrated Chlorella.

[16] showed that freeze-dried of the Tetraselmis algae has food effectiveness higher than that of Spirulina. But for Artemia salina the use of powder atomized algae of Spirulina maxima, optimizes the growth and the survival.

The curve presenting the variation of the density of rotifers according to the food mode based on the powdered spirulina shows a decrease only at D3. This could be explained by biotic factors presented mainly by microbial interactions. Indeed, in the vats of mass cultures, various species of microbes including the protozoa and the bacteria coexist and are able to have harmful effects on the growth of the rotifers. Among these microorganisms, Ciliophora was the frequent protozoa met in this culture [19].

Concerning the percentage of eggs of the rotifers, we did not observe a significant difference for the various tested food modes. In fact, throughout this work, environmental parameters, particularly the quality of the culture was maintained constant. Their variation could influence the percentage of eggs in the rotifers [20]. Although daily growth rates of rotifers nourished with powdered spirulina were satisfactory compared to those obtained with the other diets, its use as an inert food, presents a pollution problem of the breeding vat. This was observed especially on the level of the wall of the vat with fast sedimentation and an unpleasant odor. Thus, a frequent cleaning of the wall is recommended several times per day and following each distribution. Moreover, the mixing of the culture is not sufficient to ensure the maintenance in suspension of the algae powder. The only found solution was a progressive uninterrupted distribution of food [16].

\section{Conclusion}

The rotifers constitute the most used zooplanktonic preys in feeding larvae in aquaculture. However, the use of the phytoplankton as a source of food for these rotifers causes problems each in their costs and in their biochemical composition. Within this work, we followed the density of rotifers, their daily specific growth rate and the percentage of eggs of the rotifers Brachionus plicatilis cultivated on spirulina Arthrospira platensis in its live and powdered forms compared with other food modes.

The spirulina, which the production is increasing worldwide and in Tunisia, has several uses particularly as a food source and as pharmaceutical products. This is due to its high content in easily assimilating protein. In aquaculture this species could be used in the culture of the rotifers which is the basic food for the fish larvae.

This study shows that the powdered spirulina alone or added with microalgae, could be used as an inert food in feeding rotifers. But, its use in a live form did not contribute to their growth. Nevertheless, an improvement of the microbiological quality of spirulina could lead to better results.

\section{Acknowledgments:}

Authors thanks Dr; Krichen Youssef for his help in spirulina sampling

\section{Reerences:}

[1] C. James, and T. S.Abu-rezeq, Effect of different ce11 densities of Chlorella capsulata and a marine Chlorella sp. for feeding the rotifer B. plicatilis. Aquaculture. (6), 1988, 3-56.

[2] A consideration of why mass culture of the rotifer B. plicatilis with baker's yeast is instable. Hydrobiology. (147), 1987, 269-270.

[3] R. James, K. Sampath, R. Thangarathinam, and L. Vasudevan, Effect of dietary spirulina level on growth, fertility, coloration and leukocyte count in red swordtail, Xiphophorus helleri. Aquaculture - Bamidgeh 58(2), 2006, 97-104. 97

[4] Earth Food Spirulina (Ronore Enterprises, Inc.). Available on the web site http://spirulinasource.com. 1997, Updated on 15 November 1999

[5] Composition and nutritive value of blue -green algae (spirulina) and their possible use in food formulations. 3rd international congress of food science and technology, Abstracts. Washington, 1970.

[6] Spirulina, the edible microorganism, Microbiological Reviews. (47), 1983, 551-578.

[7] J.P. Jourdan, "Cultivez votre spiruline", Manuel de culture artisanale pour la production de spiruline, 1999.

[8] Monitoring of the evolving diversity of the microbial community present in rotifer cultures. Aquaculture (198), 2001, $237-252$.

[9] Bases biologiques et écologiques de l'aquaculture. Techniques et documentation, (Lavoisier Editions, Paris, 1991, 500 p).

[10] Nutritional values of live organisms used in Japan for mass propagation of fish. A review. Aquaculture (34), 1983, 115-143.

[11] A Comparison of Yield and Quality of the Rotifer (Brachionus plicatilis - L-strain) Fed Different Diets Under Aquaculture Conditions, Vietnam. Asian Fisheries Science (17), 2004, 357-363.

[12] Differences in population growth of rotifers and cladocerans raised on algal diets supplemented with yeast. Limnologica (35), 2005, 298-303.

[13] D.W. Ruben, D. Kristof, and P. Bossier, Rotifer (Brachionus "Cayman") culture performance improvement through L-carnitine addition is not related to fatty acid metabolism. Journal of Experimental Marine Biology and Ecology (393), 2010, 114-123 Gnotobiotically grown rotifer Brachionus plicatilis sensu strictu as a tool for evaluation of microbial functions and nutritional value of different food types. Aquaculture (253), 2006, 421-432. 
Effects of feeding regime and probionts on the diverting microbial communities in rotifer Brachionus culture. Aquaculture Investigations (17), 2009, 303-315 James C., et Abu-rezeq T. S., (1988). Effect of different ce11 densities of Chlorella capsulata and a marine Chlorella sp. for feeding the rotifer B. plicatilis. Aquaculure. (6), 3-56.

[16] Techniques d'élevage en masse d'un Rotifère (Brachionus plicatilis Müller) et d'un Crustacé Branchiopode (Artemia salina L.), 10th European Symposium on Marine Biology, Ostend. Belgium, Vol. (1), 1976, 331 -343.

[17] Cyst based toxicity. XI. Influence of the type of food on the intrinsic growth rate of the rotifer Brachionus calyciflorus in short chronic toxicity tests. Chemosphere 50, 2003, 367-372.

[18] R. Pourriot, and P. Champ, Consommateurs et production secondaire. In : POURRIOT R. ; CAPBLANCQ J. ; CHAMP P. \& MEYER J.A. (eds), Écologie du plancton des eaux continentales. Masson, Paris, 1982, 49-112 p.

[19] Lethality of the heliozoon Oxnerella maritima on the rotifer Brachionus rotundiformis. Fisheries Sciences. (63), $1997,543-546$.

[20] Population dynamics of planktonic rotifers in Lake Loosdrecht, The Netherlands, in relation to their potential food and predators. Freshwater Biology, (42), 1999, 77-97.

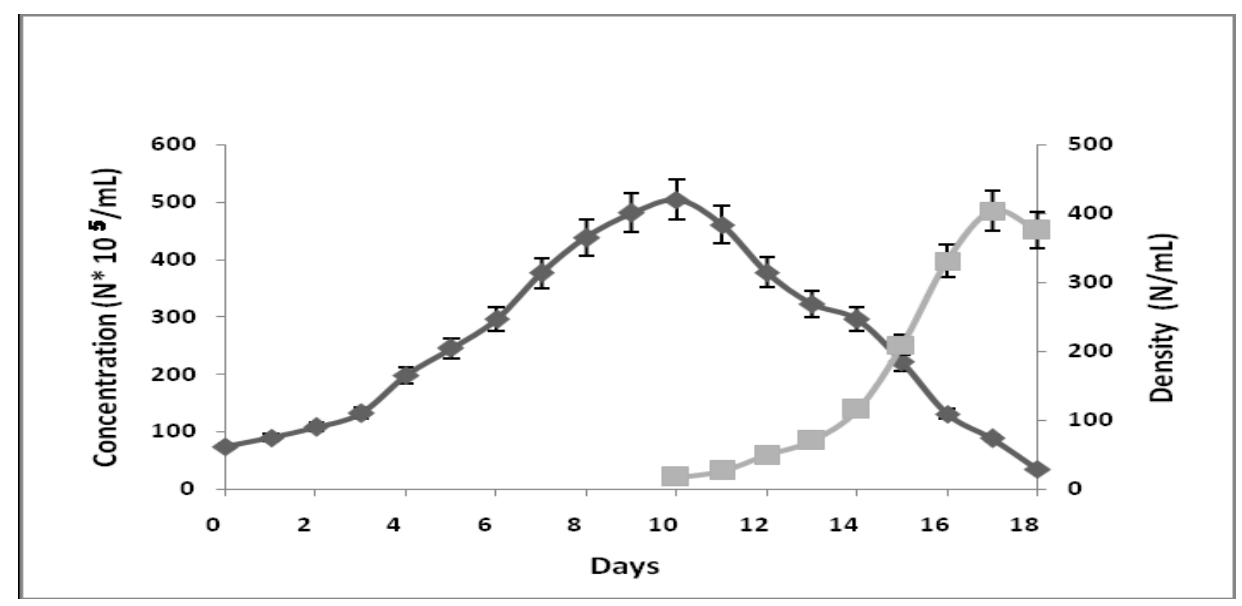

Fig.1: Change in microalgae cellular concentration and rotifer density through time.

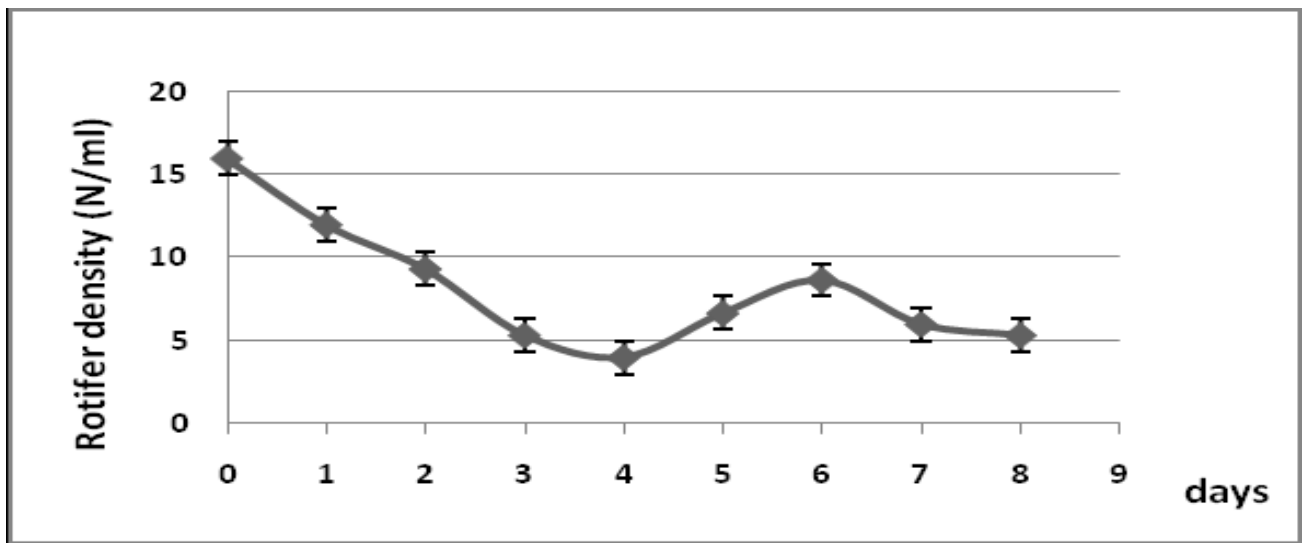

Fig.2: Variation of rotifers population densities fed with a live Spirulina

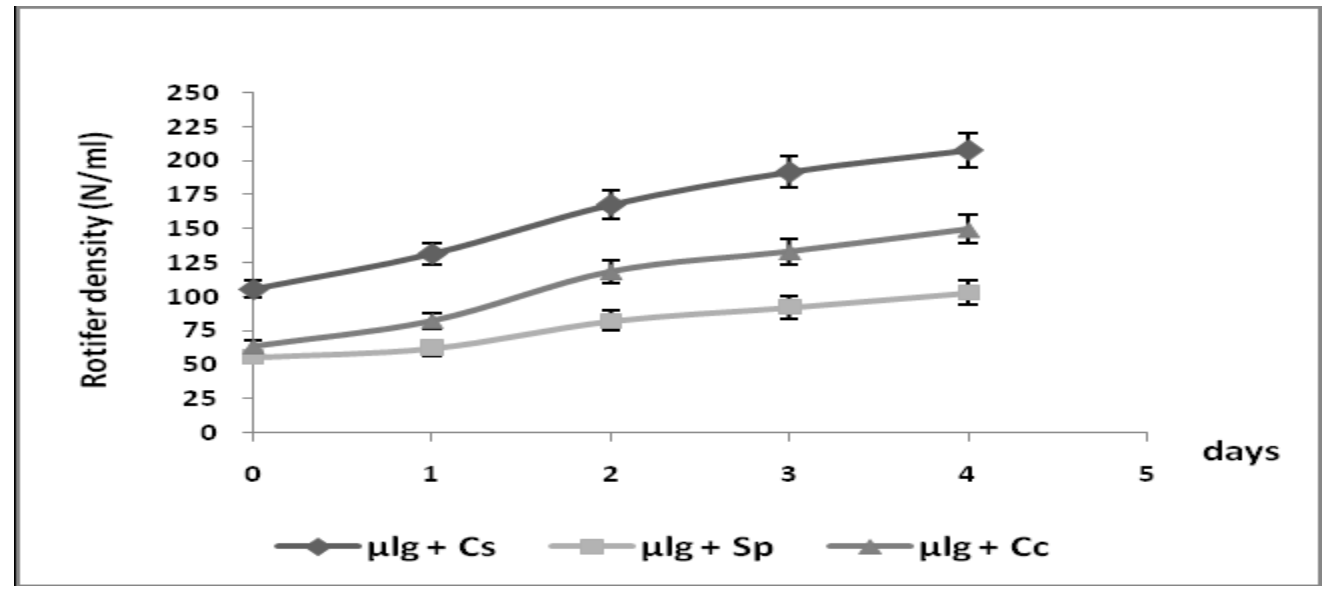

Fig.3: Variation of rotifer densities according to the various diets. $\mu \lg$ : microalgae. Cs: Culture selco, Sp: Micro-fine Spirulina, Cc: concentrated Chlorella 


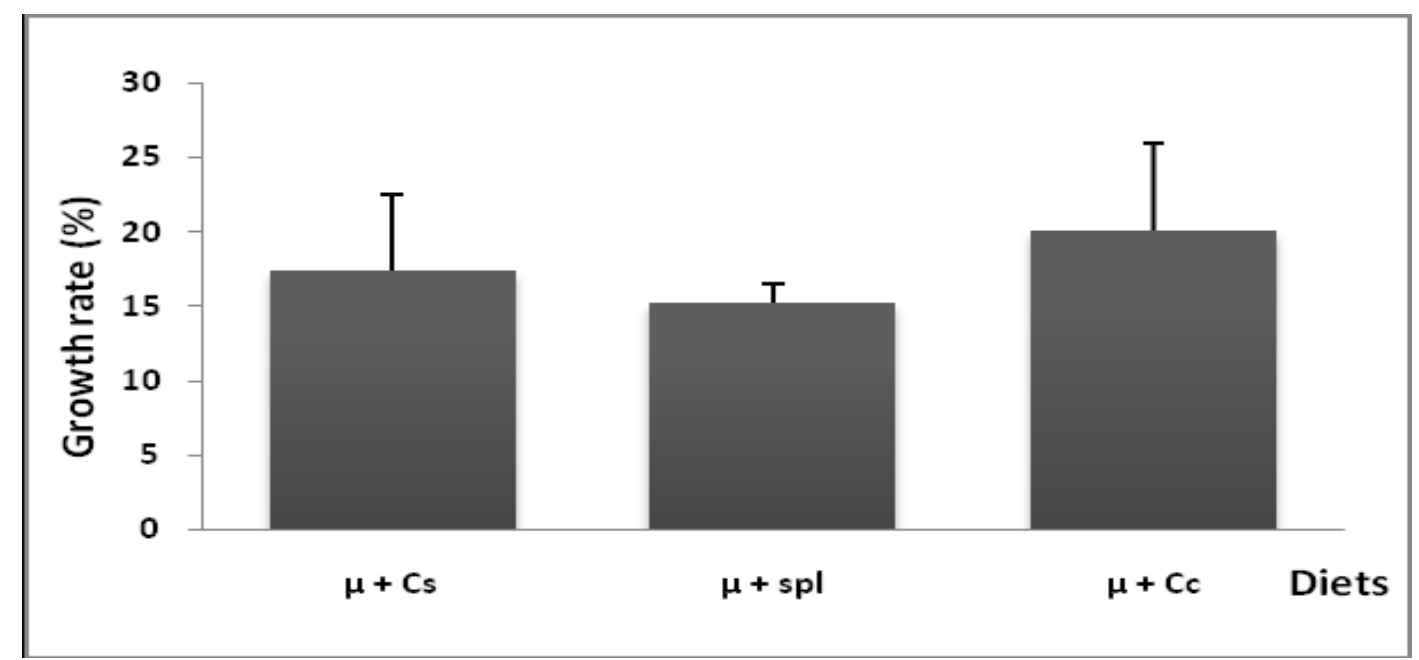

Fig. 4: Daily average Specific growth rate of rotifers according to diets. $\mu$ : microalgae. Cs:

Culture selco, Sp: microfine Spirulina, Cc: concentrated Chlorella

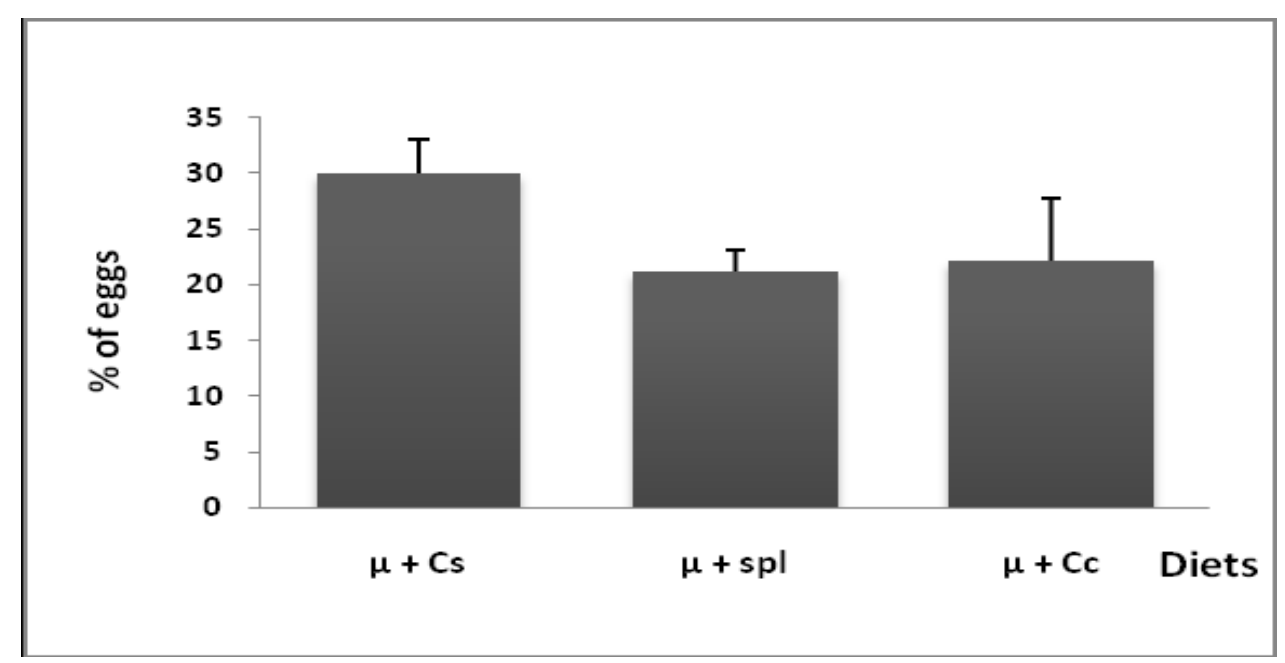

Fig. 5: Variation of rotifers eggs percentages according to different diets. $\mu:$ microalgae. Cs: Culture selco, Sp: micro-fine Spirulina, Cc: concentrated Chlorella

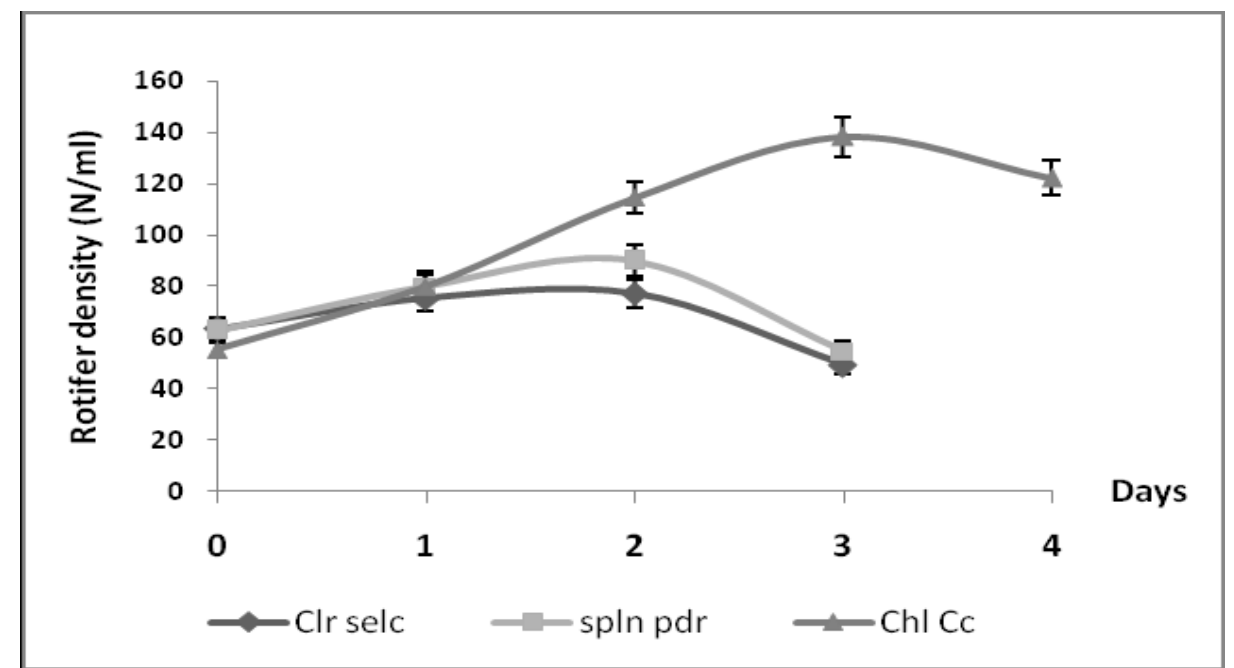

Fig.6: Variation of rotifer density according to different diets.

Clr selc : Culture Selco, Spln pdr : Spirulina powder, Ch Cc : concentrated Chlorella 


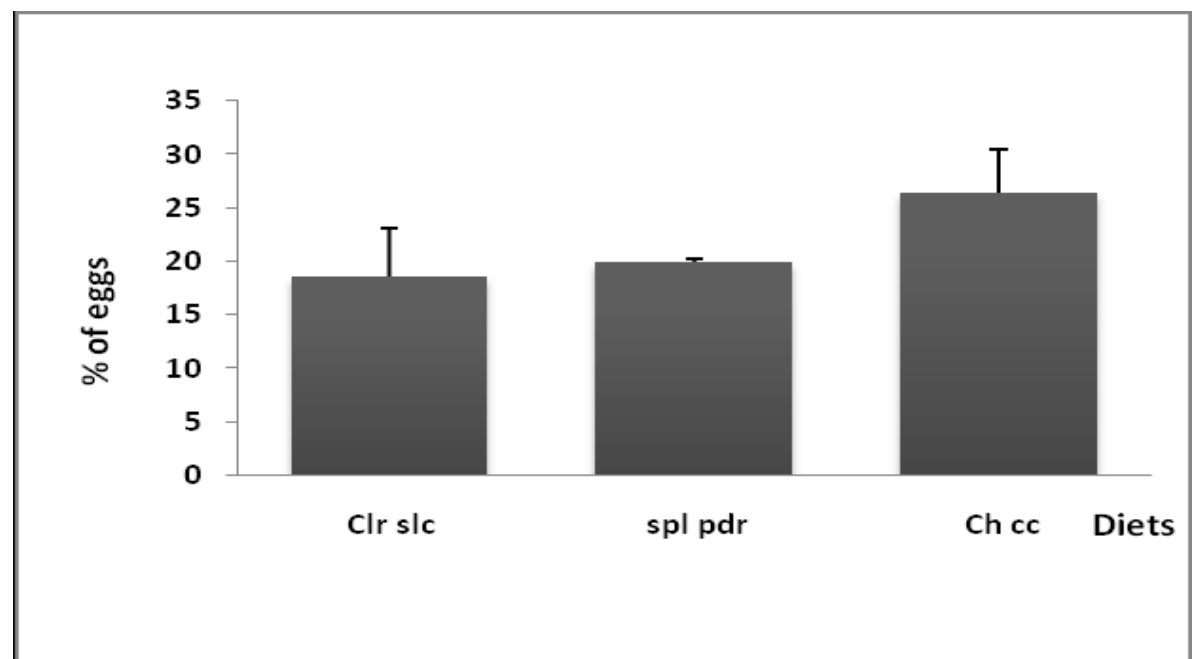

Fig. 7: Variation of rotifers eggs percentages according to different diets. Cs: Culture selco, Sp: Micro-fine Spirulina, Cc: concentrated Chlorella

Table 1: Representation of different production parameters for the microalgae species

\begin{tabular}{|c|c|c|}
\hline & Picochlorum sp. and Chlorella minitissima & Arthrospira plathensis \\
\hline $\begin{array}{l}\text { Culture } \\
\text { conditions }\end{array}$ & $\begin{array}{l}\text { Temperature: } 18-20 \\
\text { pH: } 6.5-8 \\
\text { Salinity: } 30 \% \\
\text { Light: } 2000-8000 \text { Lux }\end{array}$ & $\begin{array}{l}\text { Temperature: } 27-3 \mathrm{O} \\
\text { pH: } 8.5-11 \\
\text { Salinity: } 15 \% \\
\text { Light: } 4000-9000 \text { Lux }\end{array}$ \\
\hline Culture media & Conway culture middle (Walne, 1966) & $\begin{array}{l}\text { Zarrouk culture middle } \\
\text { (Zarrouk, 1966) }\end{array}$ \\
\hline $\begin{array}{l}\text { Culture } \\
\text { procedures }\end{array}$ & $\begin{array}{l}200 \mathrm{ml} \text { of algae inoculate into } 2 \mathrm{l} \text { sterile } \\
\text { culture middle which contains } 2 \mathrm{ml} \text { of } \\
\text { Conway solution }\end{array}$ & $\begin{array}{l}1 \text { volume Spirulina } \\
\text { introduced into } 10 \text { volumes } \\
\text { of Zarrouk culture middle }\end{array}$ \\
\hline
\end{tabular}

Table 2: Composition of different diets distributed to rotifers in tanks

\begin{tabular}{|l|l|}
\hline Diets & tank \\
\hline Microalgae + Culture Selco & 3 tanks \\
Microalgae + microfine Spirulina & 3 tanks \\
Microalgae + concentrated Chlorella & 3 tanks \\
Culture Selco & 3 tanks \\
Microfine Spirulina & 3 tanks \\
Concentrated Chlorella & 3 tanks \\
\hline
\end{tabular}

Table 3: Daily Specific growth rate of the cultures (R in \%) of D0 until D4 ( \pm standard deviation, $\mathrm{N}=3$ )

\begin{tabular}{|l|c|c|c|}
\hline & Rotifer with selco & $\begin{array}{c}\text { Culture Rotifer with powdered } \\
\text { Spiruline }\end{array}$ & $\begin{array}{c}\text { Rotifer with concentrated } \\
\text { Chlorella }\end{array}$ \\
\hline $\mathbf{R}(\%)$ & $-10,97 \pm 12,82$ & $-4,51 \pm 2,10$ & $17,59 \pm 12,95$ \\
\hline
\end{tabular}

